\title{
Radiology
}

\section{Sonographic Assessment of Portal Vein Diameter among Healthy Adults in Saudi Arabia}

\author{
Salah Albagir, $\mathrm{PhD}^{1}$; Babiker A. Wahab, $\mathrm{PhD}^{2}$; Ahmed Abdulrahman, $\mathrm{MSc}^{2}$; \\ Mogahid M.A. Zidan, $\mathrm{PhD}^{1}$; Mohammed Yousef, $\mathrm{PhD}^{3}$; Mustafa Z. Mahmoud, $\mathrm{PhD}^{4^{*}}$; \\ Ala M. A. Elgyoum, $\mathrm{PhD}^{5}$; Mohamed Adam, $\mathrm{PhD}^{6}$ \\ ${ }^{1}$ Medical Imaging Technology Department, Al-Ghad International College for Applied Medical Science, \\ Abha, Saudi Arabia \\ ${ }^{2}$ Diagnostic Technology Department, College of Medical Radiological Sciences, Sudan University of \\ Science and Technology, Khartoum, Sudan \\ ${ }^{3}$ Radiologic Sciences Program, Batterjee Medical College, Jeddah, Saudi Arabia \\ ${ }^{4}$ Radiology and Medical Imaging Department, College of Applied Medical Sciences, Prince Sattam bin \\ Abdulaziz University, Al-Kharj, Saudi Arabia \\ ${ }^{5}$ Faculty of Radiological and Nuclear Medicine Science, The National Ribat University, Khartoum, Sudan \\ ${ }^{6}$ Department of Radiological Sciences, College of Applied Medical Sciences, King Khalid University, \\ Abha, Saudi Arabia
}

\begin{abstract}
Background: The purpose of this study was to evaluate the mean values of the portal vein diameter (PVD) and establish its ultrasound reference values in healthy Saudi adults.

Methods and Results: A total of 124 healthy adult volunteers (45.2\% males and 54.8\% females, a mean age of $44.8 \pm 16$ years), presenting at the US Department of El-Karama Medical Center in Riyadh, Saudi Arabia, were recruited between November 2018 and May 2019 for this prospective study. Abdominal ultrasound scans were conducted on a Hitachi Aloka F37 machine with a curvilinear transducer with a frequency of $3.5 \mathrm{MHz}$. The data collection sheets completed for each subject included the following variables: sex, age, height, weight, and BMI $\left(\mathrm{kg} / \mathrm{m}^{2}\right)$. The mean PVD was $10.40 \pm 1.22 \mathrm{~mm}$ and higher in men $(10.7 \pm 1.1 \mathrm{~mm})$ than in women $(10.1 \pm 1.2 \mathrm{~mm})(P<0.05)$. Study results showed that PVD did not correlate with age and BMI.

Conclusion: Further large-scale studies are needed to establish ultrasound reference values for PVD in healthy Saudi adults.
\end{abstract} (International Journal of Biomedicine. 2020;10(3):211-214.)

Key Word: portal vein diameter $\bullet$ ultrasound $\bullet$ body mass index $\bullet$ age

\section{Abbreviations}

PV, portal vein; BMI, body mass index; US, ultrasound

\section{Introduction}

The portal vein (PV) is the main vessel of the portal venous system, resulting from the confluence of the splenic and superior mesenteric veins. ${ }^{(1)}$ The portal vein and hepatic artery form the liver's dual blood supply. The portal vein supplies the liver with $70-75 \%$ of its blood and the hepatic artery provides the remaining $25-30 \% .^{(2)}$ The normal portal vein diameter (PVD) can vary between $10-15 \mathrm{~mm}$ in different settings. ${ }^{(3,4)}$ The most common abnormality of the portal venous system is portal hypertension.

Various modern imaging technologies such as ultrasound, endoscopic ultrasound, computed tomography, and magnetic resonance imaging, have been widely used in the clinical 
evaluation of portal hypertension. ${ }^{(5)}$ Among these modalities, ultrasound is the most convenient and noninvasive imaging technique. Ultrasound (US) is safe, can be repeated easily, is not expensive, and is highly sensitive in detecting thrombosis in the portal vein and hepatic veins, so allowing a correct differential diagnosis of new cases of portal hypertension. ${ }^{(6-8)}$

Measurements of PVD are used as indicators for portal hypertension. However, the cutoff point for portal hypertension in the appropriate clinical setting varies in different studies. ${ }^{(4,9-11)}$

Thus, the purpose of this study was to evaluate the mean values of PVD and establish its ultrasound reference values in healthy Saudi adults.

\section{Materials and Methods}

This study is a cross-sectional prospective study done after receiving approval from all participants in this study and our institutional review board. A group of 124 healthy adult volunteers (mean age of $44.8 \pm 16$ years), presenting at the US Department of El-Karama Medical Center in Riyadh, Saudi Arabia, were recruited between November 2018 and May 2019 for this prospective study. The current study adhered to the Declaration of Helsinki and Title 4, US Code of Federal Regulations, Part 46, Protection of Human Subjects. A waiver of informed consent was conceded as per institutional rules. Participants who gave any data of a formerly known liver or vascular abnormality were excluded, also pregnant women, participants with abnormal liver tests, and participants on hepatotoxic drugs such as antituberculous and antiretroviral drugs were excluded.

Abdominal US scans were conducted on a Hitachi Aloka F37 machine (Hitachi Medical System, Tokyo, Japan) with a curvilinear transducer with a frequency of $3.5 \mathrm{MHz}$. The US examination was carried out with the subjects in the supine and right anterior oblique position. The transducer was placed in the upper abdomen immediately over the stomach (epigastrium area); the scan has been done in both the longitudinal and transverse planes to assess the PV during participant respiration when the visualization of the PV was optimal.

Measurements were made at a point where the PV crosses anterior to the inferior vena cava, with the calipers placed between the inner margins of the echogenic walls of the vessel (Fig. 1).

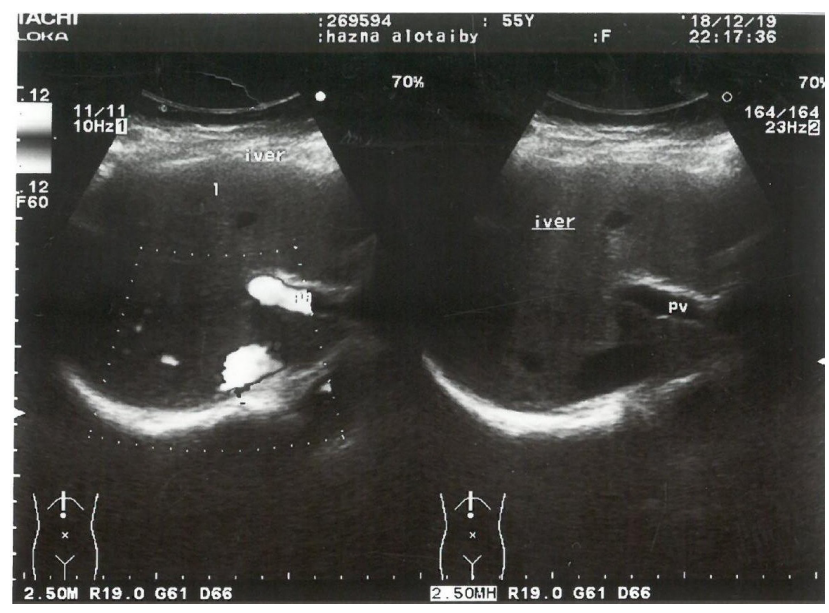

Fig. 1. Transverse view of the portal vein
Measurements were made twice by two sonographers with at least 5-year experience. The average values of the two measurements were recorded as the final value.

The data collection sheets completed for each subject included the following variables: sex, age, height, weight, and BMI $\left(\mathrm{kg} / \mathrm{m}^{2}\right)$.

The obtained data were analyzed using the standard Statistical Package for the Social Sciences (SPSS Inc., Chicago, IL, USA) version 20. Continuous variables were presented as mean \pm standard deviation (SD). For data with normal distribution, inter-group comparisons were performed using Student's t-test. Pearson's correlation coefficient (r) was used to determine the strength of the relationship between the two continuous variables. A linear regression model was constructed. A probability value of $P<0.05$ was considered statistically significant.

\section{Results and Discussion}

The study included 56 (45.2\%) males and 68 (54.8\%) females, aged between 18 and 91 years, with a mean age of $44.88 \pm 16.32$ years. The mean PVD was $10.40 \pm 1.22 \mathrm{~mm}$ $(10.1 \pm 1.2 \mathrm{~mm}$ in females and $10.7 \pm 1.1 \mathrm{~mm}$ in males, $P<0.05$ (Table 1, Table 2, Table 3, and Fig. 2). Study results found that there was no significant correlation between BMI and PVD $(P>0.05)$ (Table 4).

Table 1.

Descriptive statistics of study variables $(n=124)$

\begin{tabular}{|l|c|c|c|c|}
\hline \multicolumn{1}{|c|}{ Variables } & Minimum & Maximum & Mean & SD \\
\hline Age (years) & 18 & 91 & 44.9 & 16.3 \\
\hline Weight $(\mathrm{kg})$ & 39 & 92.5 & 90.5 & 100.7 \\
\hline Height $(\mathrm{cm})$ & 100 & 188 & 161.2 & 17.1 \\
\hline BMI $\left(\mathrm{kg} / \mathrm{m}^{2}\right)$ & 13 & 43.4 & 41.1 & 4.9 \\
\hline PVD $(\mathrm{mm})$ & 8 & 13 & 10.4 & 1.2 \\
\hline
\end{tabular}

Table 2.

Descriptive statistics of study variables in females $(n=68)$

\begin{tabular}{|l|c|c|c|c|}
\hline \multicolumn{1}{|c|}{ Variables } & Minimum & Maximum & Mean & SD \\
\hline Age (years) & 18 & 91 & 45.8 & 17.1 \\
\hline Weight $(\mathrm{kg})$ & 39 & 92,5 & 88.7 & 104.5 \\
\hline Height $(\mathrm{cm})$ & 100 & 188 & 154.4 & 19.8 \\
\hline BMI $\left(\mathrm{kg} / \mathrm{m}^{2}\right)$ & 13 & 43.4 & 38.7 & 5.0 \\
\hline PVD $(\mathrm{mm})$ & 8 & 13 & 10.1 & 1.2 \\
\hline
\end{tabular}

Table 3.

Descriptive statistics of study variables in males $(n=56)$

\begin{tabular}{|l|c|c|c|c|}
\hline \multicolumn{1}{|c|}{ Variables } & Minimum & Maximum & Mean & SD \\
\hline Age (years) & 18 & 81 & 43.7 & 15.4 \\
\hline Weight $(\mathrm{kg})$ & 45 & 79.5 & 92.8 & 96.8 \\
\hline Height $(\mathrm{cm})$ & 145 & 182 & 169.4 & 7.0 \\
\hline BMI $\left(\mathrm{kg} / \mathrm{m}^{2}\right)$ & 18.1 & 38.9 & 44.0 & 4.8 \\
\hline PVD $(\mathrm{mm})$ & 8 & 13 & 10.7 & 1.2 \\
\hline
\end{tabular}




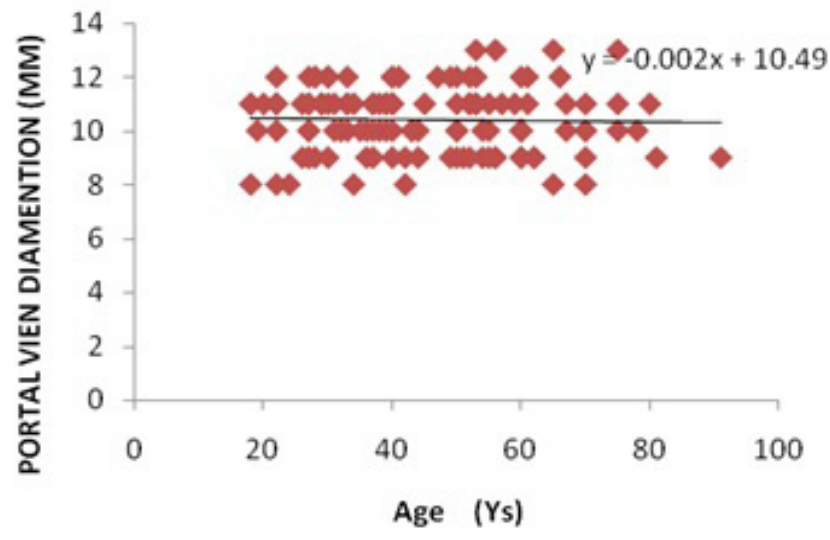

Fig. 2. Scatter diagram showing correlation between PVD and age

Table 4.

Correlation between PVD with age and BMI

\begin{tabular}{|l|l|c|c|c|}
\hline \multicolumn{2}{|c|}{ Variables } & $\begin{array}{c}\text { Age } \\
(\text { years })\end{array}$ & $\begin{array}{c}\text { BMI } \\
\left(\mathrm{kg} / \mathrm{m}^{2}\right)\end{array}$ & $\begin{array}{c}\text { PVD } \\
(\mathrm{mm})\end{array}$ \\
\hline \multirow{4}{*}{ Age (years) } & Pearson correlation & 1 & -0.149 & -0.028 \\
\cline { 2 - 5 } & Sig. (2-tailed) & - & 0.098 & 0.759 \\
\cline { 2 - 5 } & $\mathrm{n}$ & 124 & 124 & 124 \\
\hline \multirow{5}{*}{ BMI $\left(\mathrm{kg} / \mathrm{m}^{2}\right)$} & Pearson correlation & -0.149 & 1 & -0.038 \\
\cline { 2 - 5 } & Sig. (2-tailed) & 0.098 & - & 0.672 \\
\cline { 2 - 5 } & $\mathrm{n}$ & 124 & 124 & 124 \\
\hline \multirow{3}{*}{ PVD $(\mathrm{mm})$} & Pearson correlation & -0.028 & -0.038 & 1 \\
\cline { 2 - 5 } & Sig. (2-tailed) & 0.759 & 0.672 & - \\
\cline { 2 - 5 } & $\mathrm{n}$ & 124 & 124 & 124 \\
\hline
\end{tabular}

In eleven different studies implemented to measure the PVD by using abdominal US scans, the mean PVD was $10.87 \pm 0.81 \mathrm{~mm}, 8.1 \pm 0.12 \mathrm{~mm}, 10.3 \pm 1.5 \mathrm{~mm}, 11.5 \pm 1.5 \mathrm{~mm}$, $9.2 \pm 2.6 \mathrm{~mm}, 10.0 \pm 1.8 \mathrm{~mm}, 6.3 \pm 2.3 \mathrm{~mm}, 11 \pm 2.0 \mathrm{~mm}, 9.36 \pm 1.65$ $\mathrm{mm}, 9.60 \pm 1.41 \mathrm{~mm}$, and $10.02 \pm 0.89 \mathrm{~mm}$, respectively. ${ }^{(12-22)}$

The mean PVD in the current study was compatible with the results of Usman et al. $(10.87 \pm 0.81 \mathrm{~mm}){ }^{(14)}$ Hawaz et al. $(10.3 \pm 1.5 \mathrm{~mm})^{(13)}$, Bhattacharya et al. ${ }^{(12)}(10.0 \pm 1.8 \mathrm{~mm})$, and Adeyekun et al. $(10.02 \pm 0.89 \mathrm{~mm})^{(15)}$. This might be due to the methods adopted by these studies for PVD measurements were all done using the trans-abdominal approach and similar age group.

In the studies conducted by Weeb et al. ${ }^{(17)}$, Ukperi ${ }^{(18)}$, Yazdi and Sotoudeh ${ }^{(19)}$, and Ongoiba et al. ${ }^{(20)}$, the mean PVD was $6.3 \pm 2.3 \mathrm{~mm}, 8.1 \pm 0.12 \mathrm{~mm}, 9.36 \pm 1.65 \mathrm{~mm}$, and $9.2 \pm 2.6$ $\mathrm{mm}$, respectively. These values were lower than our results (Table 1, Table 2, Table 3). These differences in diameters could be due to the smaller sample size when compared to the other study. Also, PVD in the current study was higher than the diameters reported by Anakwue and Tsebi $(11 \pm 2.0$ $\mathrm{mm})^{(15)}$ and Weinerb et al. $(11.5 \pm 2 \mathrm{~mm})^{(16)}$. To our knowledge, the difference between our study and theses previous studies could be due to different ethnic groups and races, with varying sample sizes.
Some studies had documented PVD to vary with age, gender, and BMI. In our study, PVD was higher in men than in women (Table 2 and Table 3). The current findings regarding the gender were different than the results of other studies, (13,15,22-24) which found no significant influence of gender on PVD. Moreover, the influence of age on PVD has been documented also in these various researchers with varied results. ${ }^{(13,15,22-25)}$ In the current study, we noticed that there was no significant correlation between participants' age and PVD (Fig.2) and it was in agreement with the reports of other researchers ${ }^{(12,1315,22-25)}$ reported no statistically significant influence of age on PVD.

Study results showed that there was no significant correlation between BMI and PVD. Our results are in agreement with the data obtained by Adeyekun and Tesbi ${ }^{(15)}$. However, these results were not similar to previous studies conducted by Gosh et al. ${ }^{(26)}$ and Saha et al., ${ }^{(22)}$ in which the researchers found a positive correlation between BMI and PVD. Raut and Bahetee $^{(27)}$ reported a positive correlation between PVD and other anthropometric parameters. The knowledge of these normal variations is essential for surgeons, sonologists, and sonographers during the diagnosis of problems that may relate to the portal system.

This study is limited by the heterogeneity of the population because of the randomized selection process, which may influence the exactness of our outcomes and lessen the intensity of our conclusions since it makes other age groups have a lower factual validity if applied in future investigations.

In conclusion, this study established baseline values in the normal range of PV diameter in apparently healthy Saudi adults and found that PVD positively correlates with anthropometric variables. In addition, this study proofs that the mean PVD in males was higher than in females while BMI and age had no significant correlation with PVD. Further large-scale studies are needed to establish ultrasound reference values for PVD in healthy Saudi adults.

\section{Acknowledgements}

This publication was supported by the Deanship of Scientific Research at Prince Sattam bin Abdulaziz University, Alkharj, Saudi Arabia.

\section{Competing Interests} interests.

The authors declare that they have no competing

\section{References}

1. Carneiro C, Brito J, Bilreiro C, et al. All about portal vein: a pictorial display to anatomy, variants and physiopathology. Insights Imaging. 2019;10(1):38. Published 2019 Mar 21. doi:10.1186/s13244-019-0716-8

*Corresponding author: Professor Mustafa Z. Mahmoud, Radiology and Medical Imaging Department, College of Applied Medical Sciences, Prince Sattam bin Abdulaziz University, E-mail: m.alhassen@psau.edu.sa,PO Box: 422, Zip Code: 11942, Al-Kharj, Saudi Arabia. 
2. Corness JA, McHugh K, Roebuck DJ, Taylor AM. The portal vein in children: radiological review of congenital anomalies and acquired abnormalities. Pediatr Radiol. 2006;36(2):87-171. doi:10.1007/s00247-005-0010-4

3. Tirumani SH, Shanbhogue AK, Vikram R, Prasad SR, Menias CO. Imaging of the porta hepatis: spectrum of disease [published correction appears in Radiographics. 2014 May-Jun;34;(3):848]. Radiographics. 2014;34(1):73-92. doi:10.1148/rg.341125190

4. Geleto G, Getnet W, Tewelde T. Mean Normal Portal Vein Diameter Using Sonography among Clients Coming to Radiology Department of Jimma University Hospital, Southwest Ethiopia. Ethiop J Health Sci. 2016;26(3):237-242. doi:10.4314/ejhs.v26i3.6

5. Chung-Chieng Wu. Ultrasonographic Evaluation of Portal Hypertension and Liver Cirrhosis J Med Ultrasound 2008;16(3):188-193

6. Mahadevan V. Anatomy of the pancreas and spleen. Surgery (Oxford). 2019;37(6):297-301

7. Margini C, Berzigotti A. Portal vein thrombosis: The role of imaging in the clinical setting. Dig Liver Dis. 2017;49(2):113-120. doi:10.1016/j.dld.2016.11.013

8. Procopet B, Berzigotti A. Diagnosis of cirrhosis and portal hypertension: imaging, non-invasive markers of fibrosis and liver biopsy. Gastroenterol Rep (Oxf). 2017;5(2):79-89. doi:10.1093/gastro/gox012

9. Weinreb J, Kumari S, Phillips G, Pochaczevsky R. Portal vein measurements by real-time sonography. AJR Am J Roentgenol. 1982;139(3):497-499. doi:10.2214/ajr.139.3.497 10. Al-Nakshabandi NA. The role of ultrasonography in portal hypertension. Saudi J Gastroenterol. 2006;12(3):111117. doi:10.4103/1319-3767.29750

11. Schabel SI, Rittenberg GM, Javid LH, Cunningham J, Ross P. The "bull's-eye" falciform ligament: a sonographic finding of portal hypertension. Radiology. 1980;136(1):157159. doi:10.1148/radiology.136.1.7384492

12. Bhattacharya J, Dasb A, Bhowmikc A. Sonographical Assessment of Portal Vein Diameter in Northern Part of West Bengal, India. Oct Jour Env Res. 2013;1(3):231-234

13. Hawaz Y, Admassie D, Kebede T. Ultrasound Assessment of Normal Portal Vein Diameter in Ethiopians Done at Tikur Anbessa Specialized Hospital. East Cent Afr J Surg. 2012;17(1):90-93.

14. UsmanAU, Ibinaiye P,Ahidjo A, TahirA, Sa'ad ST, Mustapha Z, Tahir N, Garko S. Ultrasound Determination of Portal Vein
Diameter in Adult Patients with Chronic Liver Disease in NorthEastern Nigeria. Sub-Saharan Afr J Med 2015;2(2):57-63.

15. Adeyekun AA, Tsebi HB. Grey-scale sonographic evaluation of portal vein diameter in healthy Nigerian adults. Journal of Medicine and Biomedical Research 2014;13(1):17-24.

16. Weinreb J, Kumari S, Phillips G, Pochaczevsky R. Portal vein measurements by real-time sonography. AJR Am J Roentgenol. 1982;139(3):497-499. doi:10.2214/ajr.139.3.497 17. Webb LJ, Berger LA, Sherlock S. Grey-scale ultrasonography of portal vein. Lancet. 1977;2(8040):675-677. doi:10.1016/s0140-6736(77)90492-5

18. Ukperi OS. Ultrasonographic measurement of normal portal vein diameter in Nigerian adults. Dissertation submitted to the faculty of radiology, West African college of surgeons. 2010

19. Yazdi HR, Sotoudeh H. Assessment of Normal Doppler Parameters of Portal Vein and Hepatic Artery in 37 Healthy Iranian Volunteers. Iran J Radiol 2006; 4: 213-216.

20. Ongoiba N, Sissoko F, Ouologuem I, S Berete, A K Traore, S Sidibe, M Toure, AD Keita, A K Koumare. Veine porte: anatomie échographique [Portal vein: echographic anatomy]. Morphologie. 2003;87(277):29-32. [Article in French]

21. Luntsi G, Sani M, Zira JD, Ivor NC, Garba SH. Sonographic assessment of the portal vein diameter in apparently healthy adults in a Northern Nigerian population. Afr Health Sci. 2016;16(4):1163-1168. doi:10.4314/ahs.v16i4.35

22. Saha N, Sarkar R, Singh MM. Portal vein diameter in a tertiary care centre in North-East India. IOSR Journal of Dental and Medical Sciences. 2015;14(1):114-117.

23. Raza Siddiqui T, Hassan N, Gul P. Effect of anthropometrical measurements on portal vein and hepatosplenic span. Pak J Med Sci. 2013;29(4):1077-1080. doi:10.12669/pjms.294.3617

24. Goyal AK, Pokharna DS, Sharma SK. Ultrasonic measurements of portal vasculature in diagnosis of portal hypertension. A controversial subject reviewed. J Ultrasound Med. 1990;9(1):45-48. doi:10.7863/jum.1990.9.1.45

25. Patriquin HB, Perreault G, Grignon A. Boisvert J, Filiatrault D, Garel L, Blanchard H. Normal portal venous diameter in children. Pediatr Radiol. 1990;20(6):451-453. doi:10.1007/BF02075206

26. Ghosh TN, Bernerjee M, Basu S, Das R, Kumar P, De S, Ghosh MK, Ganguly S. Assessment of normal portal vein diameter in children. Trop Gastroenterol. 2014;35(2):79-84. 27. Raut RS, Bahetee BH. Study of Anatomical Dimensions of Portal Vein. Sch J App Med Sci. 2015;3(3E):1343-1345. 